\title{
Heat Transfer on a Double Wedge Geometry in Hypervelocity Air and Nitrogen Flows
}

\author{
A.B. Swantek*, and J. M. Austin ${ }^{\dagger}$ \\ University of Illinois, Urbana, Illinois, 61801
}

\begin{abstract}
We investigate shock wave/boundary-layer interaction and resulting heat transfer in hypervelocity double wedge flows. An expansion tube is used to generate air and nitrogen flows with stagnation enthalpies ranging from 2.1-8.0 MJ/kg and Mach numbers from 4-7. The range of free stream conditions were selected to investigate the impact of thermochemical effects by i) systematically varying the chemical composition from nitrogen to air while maintaining constant the stagnation enthalpy or the Mach number, and ii) varying the stagnation enthalpy. Flow features are visualized with schlieren photography, and heat transfer is measured using fast response coaxial thermocouples. Data are presented for both nitrogen and air test conditions with eight cases in total. Current results indicate significantly different behavior in flows with enthalpies as low as $4 \mathrm{MJ} / \mathrm{kg}$ between air and nitrogen test conditions.
\end{abstract}

\section{Nomenclature}

Subscript

$e \quad$ Edge of the boundary layer

$w \quad$ Wall

$\infty \quad$ Freestream

Superscript

* Reference condition

\footnotetext{
*Graduate Student, Department of Aerospace Engineering, Student Member AIAA

$\dagger$ Associate Professor, Department of Aerospace Engineering, Associate Fellow AIAA
} 


\section{Introduction}

The flow over a double wedge model is a canonical problem in the study of hypersonic shock waveboundary layer interactions. Flow field computations are very sensitive to the choice of thermochemical model, ${ }^{1}$ and thus make the problem ideal for model verification. The flow field contains complex, but coupled phenomena, including: boundary layer separation, shock and shear layers interaction, and shock impingement. These are illustrated in Figure 1.

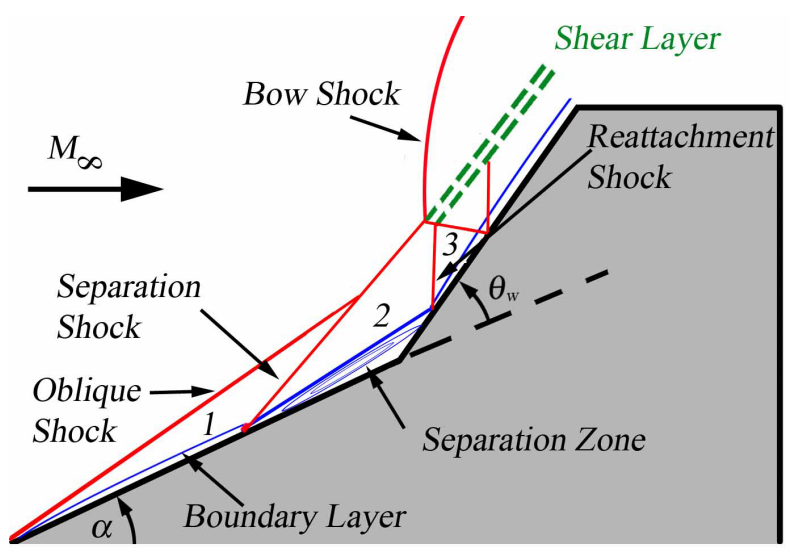

Figure 1. Schematic of separated double wedge flow with regions labeled following Davis and Sturtevant. ${ }^{2}$ Some wave interactions have been omitted for clarity.

Double wedge and cone configurations have been studied computationally and experimentally by numerous researchers, particularly in nitrogen flows. Olejniczak et al. ${ }^{1}$ performed simulations and experiments in nitrogen, and found that aft body heat transfer levels could be matched, but not the peak heating location, and the fore body separation heating could be matched, but not the separation zone size. A concurrent paper by Olejniczak et al. ${ }^{3}$ focused on the different types of shock interactions that occur over the double wedge. They studied the classical shock interactions characterized by Edney ${ }^{4}$ and identified a new type of interaction with a regular shock reflection from the triple point to the fore body, rather than the aft body. Olejniczak et al. ${ }^{5}$ extended their previous work to investigate the effect of different thermochemical models, but still found discrepancies in the separation zone size or peak heating location.

Perhaps the most comprehensive work relevant to our study is that of Davis and Sturtevant, ${ }^{2}$ who investigated separation zone length scaling and heat transfer theoretically, computationally, and numerically in a hypersonic nitrogen flow. Building on triple deck theory ${ }^{6-8}$ they derived a partial scaling for the separation zone with a new parameter $\Lambda_{1}$ shown in Equation 1. In a previous work, ${ }^{9}$ we have investigated the application of this scaling to the flow over a double cone model, as well as the current double wedge experiments.

$$
\frac{L_{s e p}}{x_{1}} \propto \frac{\Lambda_{1}}{\gamma^{3 / 2} M_{1}^{3}}\left(\frac{p_{3}-p_{2}}{p_{1}}\right)^{3 / 2}
$$

Subscripts indicate regions corresponding to Figure 1. $\Lambda_{1}$ is a parameter unique to the work of Davis and Sturtevant which describes the effect of wall to boundary layer edge temperature ratio. It is defined as

$$
\Lambda_{1}=\left(\frac{\mu_{w}}{\mu^{*}}\right)\left(\frac{T^{*}}{T_{e}}\right)\left(\frac{T_{w}}{T_{e}}\right)^{1 / 2}
$$

The above studies considered nitrogen flows to simplify the thermochemical modeling. In air flows, simulations and experiments show considerable discrepancies at high enthalpies $(\gtrsim 5 \mathrm{MJ} / \mathrm{kg})$ with significant thermochemical activity, in spite of good agreement at lower enthalpies. ${ }^{10-12}$ For example, simulations predict a decrease in the separation length with increasing freestream enthalpy, but this is not observed experimentally. ${ }^{13}$ In another study investigating possible freestream effects, Nompelis and Candler ${ }^{10}$ simulated the spectroscopic measurements of freestream NO concentration performed by Parker et al. ${ }^{14}$ Simulations overpredict the amount of freestream NO by a factor of three, which is outside the experimental error.

In the present work, we extend these previous studies by utilizing an expansion tube facility to access a broad range of test conditions. The range of test conditions allows the degree to which thermochemical 
effects influence the flow field to be tuned by changing the freestream chemical composition from nitrogen to air while keeping other parameters, such as Mach number or stagnation enthalpy constant. The stagnation enthalpy can be varied from 2.1 to $8.8 \mathrm{MJ} / \mathrm{kg}$ The expansion tube is able to produce thermochemically "clean" flows with minimal freestream dissociation, as the gas is never stagnated and is accelerated by an unsteady expansion fan, rather than a nozzle. More details on the facility are given below.

\section{Experimental}

Experiments are performed in the Hypervelocity Expansion Tube (HET) at the University of Illinois. The HET is a $9.14 \mathrm{~m}$ long expansion tube facility, consisting of a driver, driven, and accelerator section all with an internal diameter of $150 \mathrm{~mm}$. Facility capabilities include: operating at Mach numbers of 3.57.5 and achieving stagnation enthalpies of 2.1-8.8 MJ/kg. Further details of facility instrumentation and operation can be found in Dufrene et al. ${ }^{15}$ Four test conditions at various enthalpies are utilized for this study; parameters are caclulated using 1-D unsteady gas dynamics, Table 1. Test conditions are identified by the Mach number and stagnation enthalpy. Each of the four test conditions shown can be achieved using both air and nitrogen, resulting in eight different test cases in total. Changes in freestream parameters are less than $0.5 \%$ between nitrogen and air.

Table 1. Theoretical parameters for HET test conditions.

\begin{tabular}{ccccc}
\hline \hline Freestream Parameters & M5_4 & M7_2 & M7_8 & M4_3.6 \\
\hline Mach Number & 5.12 & 7.11 & 7.14 & 4.01 \\
Static temperature, $K$ & 676 & 191 & 710 & 853 \\
Static pressure, $k P a$ & 8.13 & 0.391 & 0.78 & 18.3 \\
Velocity, $\mathrm{m} / \mathrm{s}$ & 2664 & 1972 & 3812 & 2340 \\
Density, $\mathrm{kg} / \mathrm{m}^{3}$ & 0.042 & 0.0071 & 0.0038 & 0.0747 \\
Test Time, $\mu \mathrm{s}$ & 361 & 327 & 242 & 562 \\
Unit Reynolds Number, $10^{6} / \mathrm{m}$ & 3.42 & 1.10 & 0.435 & 4.64 \\
Stagnation Enthalpy, $\mathrm{MJ} / \mathrm{kg}$ & 4.1 & 2.1 & 8.0 & 3.6
\end{tabular}

A double wedge model $\left(\alpha=30^{\circ}, \theta=25^{\circ}, L=50.8 \mathrm{~mm}\right.$, and $\left.b=101.6 \mathrm{~mm}\right)$ is machined from A2 tool steel. The model is dimensioned according the criteria summarized by Davis and Sturtevant, ${ }^{2}$ and is designed as a one half scale version of theirs. The minimum $\delta_{1} / b$ value is $\sim 125$, which exceeds the recommended minimum of 85. A PCO1600 digital camera with a Nikon zoom lens $(f=70-300 \mathrm{~mm})$ in a Z-type schlieren system is used for visualization. Illumination is provided by a Xenon spark gap with a pulse width time of $20 \mathrm{ns,}$ effectively freezing the flow features. The model is instrumented with nineteen, $1 \mu$ s response time, coaxial thermocouples ${ }^{16}(d=2.4 \mathrm{~mm})$ for heat transfer measurements at sixteen different streamwise locations. Three of the stream wise locations have two gauges to asses any spanwise variation. The spacing of gauges varies along the model and gauges are clustered around areas of interest (boundary layer separation, shock boundary layer interaction, etc...). The instrumented model is shown in Figure 2. Error bars on the heat transfer data due to gauge uncertainties are $8 \%$.

\section{Results}

\section{III.A. Schlieren Images}

Sample schlieren images of flow over the double wedge are shown in Figures 3(a)-(d) for four test conditions: M5_4 in nitrogen and air, and M7_8 in nitrogen and air. Both of the M7_8 experiments appear to show generally laminar flow, while the M5_4 images appear to have large regions of fluctuating flow. This is consistent with the fact that the unit Reynolds number of the the M5_4 test condition is nearly an order of magnitude larger that that of the M7_8 conditions, Table 1. Both sets of images show at least one distinct triple point with a shear layer and transverse wave. The wave interaction observed in the M5_4 test conditions appear more complex than in the M7_8 conditions with a possible secondary triple point 


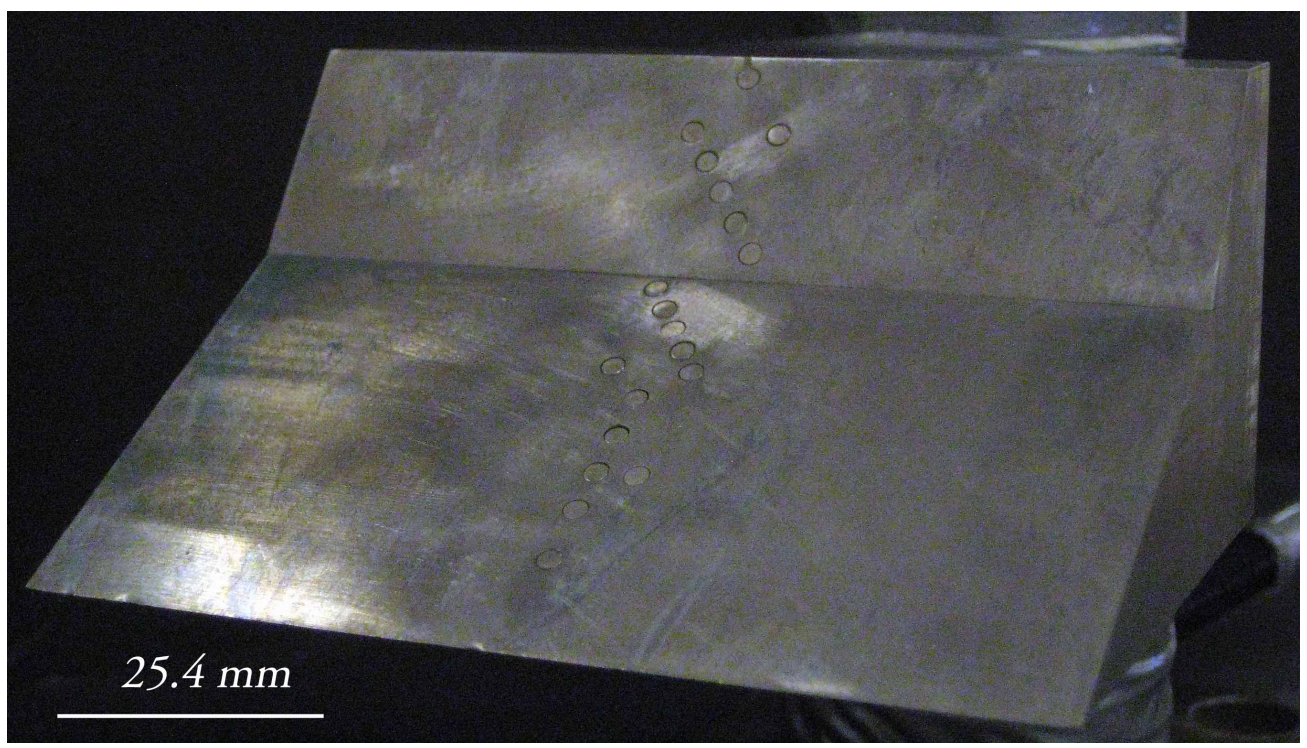

Figure 2. The experimental double wedge model used in the current study. The coaxial thermocouple gauges can be seen along the center of the model. Note: Some gauges are staggered to increase spatial resolution.

appearing. The shear layer turns upward to align with the flow above the second wedge, and in the case of the higher Reynolds number condition, it is still visible some distance after the compression. It appears that the intersection of the reattachment shock with the shear layer is the mechanism for turning the shear layer upwards along the aft wedge.

The effects of thermochemistry are very apparent in the images. A distinct region with natural flow luminescence indicating a region of relatively hot gas in behind the bow shock can be observed in Figure 3(c). This is in contrast to the region on the other side of the shear layer which contains relatively cold, high speed flow. Both sets of test conditions exhibit bow shocks which reduced shock standoff distance for the air conditions in comparison to nitrogen. This agrees with normal shock equilibrium calculations using the $S D$ Toolbox ${ }^{17}$ and Cantera, ${ }^{18}$ which predict higher post-shock densities for the air conditions. In the M5_4 nitrogen flow, Figure 3(a), we do not observe a wave emanating near the corner to turn the flow up the aft portion of the model, as is evident in images for the air flow, Figure 3(b). The departure from laminar behavior is observed further upstream in the case of the nitrogen, when compared to the air. Lastly, the regions of largest flow luminescence in these images both appear to occur between gauges $L$ and $M$. For the case of the the M7_8 air condition, the shock impingement on the aft wedge and region of largest flow luminescence are seen to move noticeably downstream, compared to the nitrogen. This behavior is most likely coupled with the corresponding shift in the triple point location.

Polar calculations of the triple point structure and wave interactions in the different conditions have been performed, building on our previous studies. ${ }^{19,20}$ Calculations are performed for a direct oblique-bow shock interaction. Two examples of these plots are shown in Figure 4 for the M7_2 and the M7_8 test conditions. Both frozen (Fr.) and equilibrium (Eq.) solutions are presented.

Not surprisingly, the equilibrium calculation and the frozen calculations do not differ significantly at the $2 \mathrm{MJ} / \mathrm{kg}$ enthalpy condition. The equilibrium effects seen in the $8 \mathrm{MJ} / \mathrm{kg}$ case influence the polars in two ways. First, in Figure 4(b), the post shock pressure for the case of strong shocks is reduced for the equilibrium calculation, when compared with the frozen calculation. Equilibrium chemistry has the effect of reducing the shear layer angle, compared with the frozen calculations. Calculations like these have been done for every schlieren data set. Three features calculated are: the bow shock angle, the transmitted shock angle, and the shear layer angle, and these are compared with experimental measurements.

In general, the best agreement between theory and experiment across all test conditions is with nitrogen as a test gas. Of all the test conditions the best agreement with shock polar calculations is the M7_2 test condition. The most disagreement between theory and experiment is the M4_3.6 condition. Error in the transmitted shock angle is seen up to $50 \%$, while at most for any other test condition they are $15 \%$. This may be a result of unsteady behavior. This condition also has the largest disagreement in the shear layer angle as well. Time-resolved schlieren imaging experiments are in process to investigate potential unsteadiness 


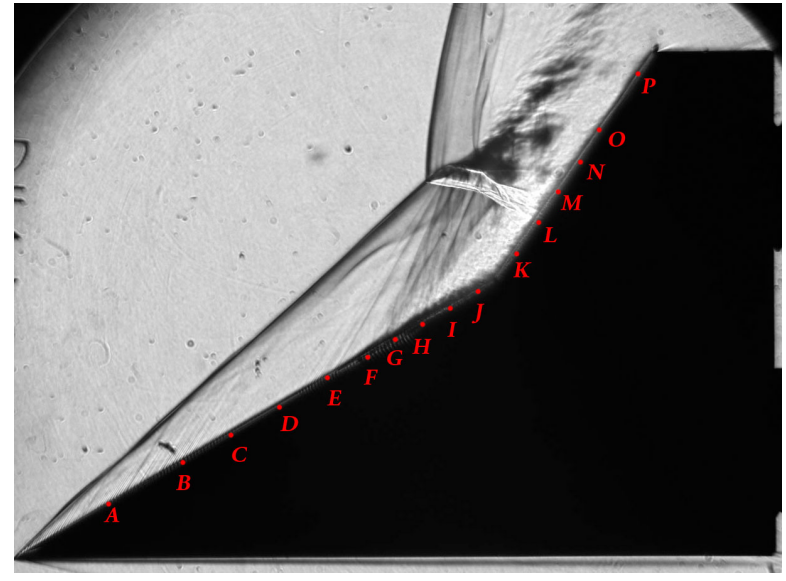

(a)

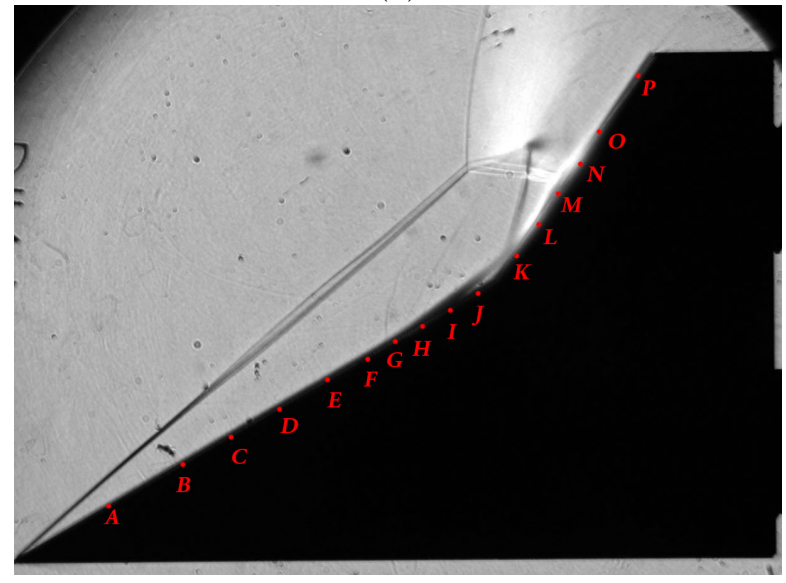

(c)

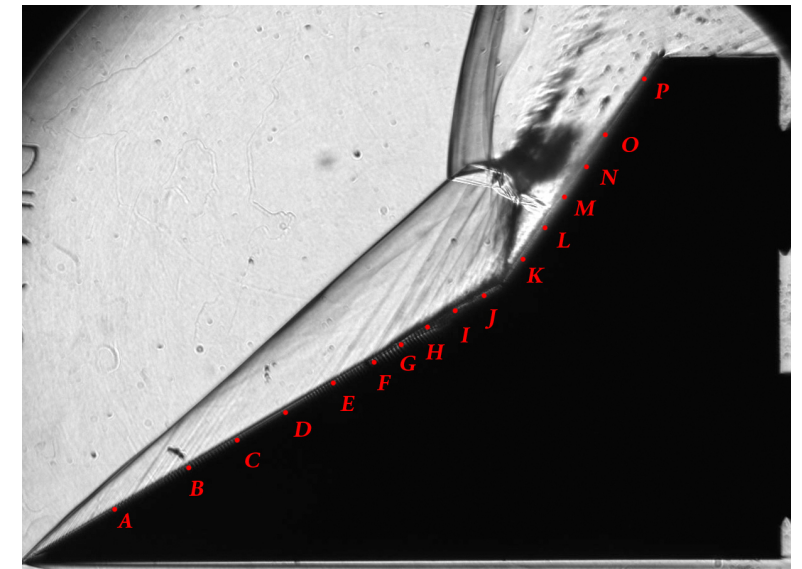

(b)

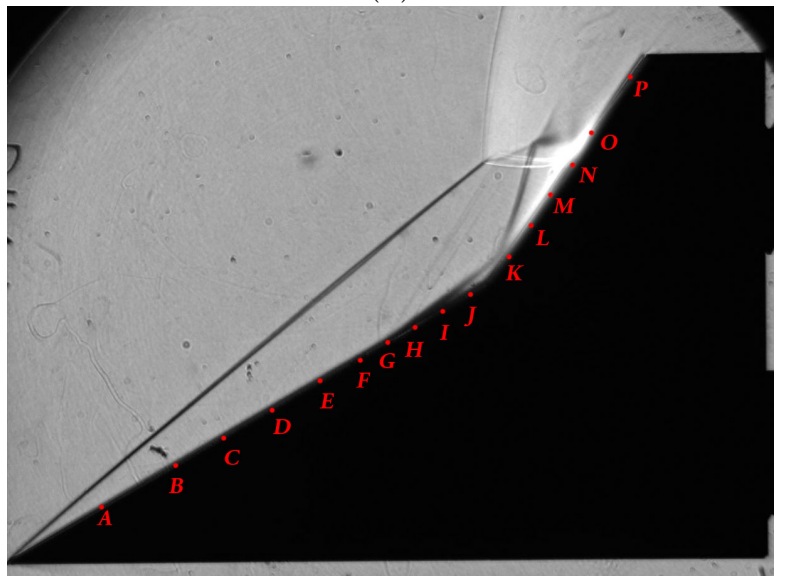

(d)

Figure 3. Schlieren images of the double wedge model (flow from left to right) in nitrogen at the (a) M5_4 and (c) M7_8, and air at the (b) M5_4 and (d) M7_8 test conditions. Bright regions are due to luminescence. All four cases appear to have type IV interactions.

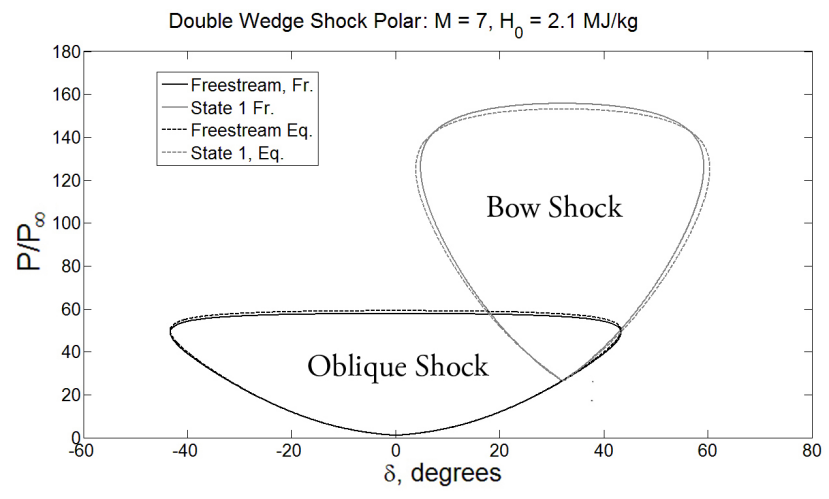

(a) M7_2

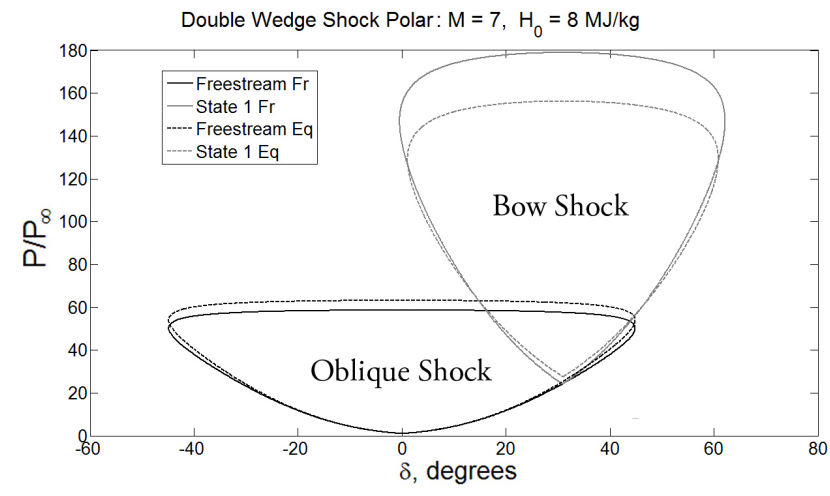

(b) M7_8

Figure 4. Polar calculations for the primary triple points. Calculations are performed for air conditions using a direct oblique-bow shock interaction. 
further.

\section{III.B. Heat Transfer Results}

Using the fast response thermocouples discussed in Section II, heat transfer profiles are constructed over the double wedge model for each of the eight different test conditions. Current capabilities limit data acquisition to 10 channels. As there are 19 gauges on the model, two shots are required to capture all the points. At least three full data sets are obtained for each test condition to assess repeatability. In total $\sim 60$ experiments were carried out establish working gauges, as well as to profile all of the test conditions. Heat transfer values are averaged after a steady test time has been established; each transient heat transfer trace is inspected individually to ensure the useful test time. In addition to averages, the standard deviation of heat flux is also recorded.

In the following section, each set of heat transfer data are presented along with the schlieren images shown in Section III.A. The error bars in the heat transfer are $\pm 8 \%$ of the absolute value. The location of the hinge is shown by a vertical dashed line, and $x$ location is normalized by the length of the first wedge face $\mathrm{L}$. (The $\mathrm{x}$ axis is in freestream flow direction, thus, the hinge is not located at $x / L=1$ ). Predictions for laminar flat plate boundary layer theory are presented for reference. Davis and Sturtevant found reasonable agreement between flat plate and wedge forebody heat transfer measurements.

\section{III.B.1. M7_2 Test Condition}

Heat transfer data for nitrogen and air along with the corresponding schlieren images are shown in Figures 5(a) and (b). In Figure 5(c) both heat transfer distributions are overlaid. The forward wedge experiences laminar heat transfer behavior on the section upstream of separation. Possibly due to low signal to noise ratio (nearly an order of magnitude smaller than any other test condition), there is large variability in the length separation zone. On the aft face there is a sudden increase in heat transfer, and peak values are $\sim 1.3 \mathrm{MW} / \mathrm{m}^{2}$ at gauge $\mathrm{M}$. This corresponds roughly with the location of shock impingement on the aft face. The combined overlay of both data sets in Figure 5(c) shows that, as expected, the heat transfer does not differ significantly between air and nitrogen flows.

\section{III.B.2. M4_3.6 Test Condition}

Heat transfer data for the nitrogen and air along with the corresponding schlieren images are shown in Figures 6(a) and (b). In Figure 6(c) both heat transfer distributions are overlaid. On the forward wedge, there is an immediate departure from laminar heating profiles. Additionally, very little difference is observed between the two test conditions. Data from gauge $\mathrm{G}$ is missing due to damage to the gauge. In both Figures, between gauges $\mathrm{F}$ and $\mathrm{H}$, there is a large differential between the heating values (an increase of approximately a factor of two). This may be due to the the shock interactions that are seen to occur in this area in the images. Peak heating on the aft wedge is approximately $13 \mathrm{MW} / \mathrm{m}^{2}$ for the nitrogen, and approximately $14 \mathrm{MW} / \mathrm{m}^{2}$ for air, both occur at gauge $\mathrm{M}$. In general on the aft wedge, the heat transfer rates in air are slightly higher than those in nitrogen. This is especially true in the area of peak heating.

\section{III.B.3. M5_4 Test Condition}

Figures 7(a) and (b) show the heat transfer for the nitrogen and air along with the corresponding schlieren images. In Figure 7(c) heat transfer distribution for nitrogen and air are overlaid. On the forward wedge, laminar heat transfer behavior is observed in both gases. As the boundary layer behavior deviates from the laminar condition in the images, the heat transfer is seen to increase as expected. As the Reynolds number is smaller than the M4_3.6 case, the increase occurs further downstream. Interestingly, the nitrogen experiences a much larger heating value at gauge $G$, when compared with the air. This may be due to two things: a lack of gauge resolution may not be detecting the actual peak heat transfer (the location may have been shifted for air), or some sort of interaction between the shock and boundary layer unique to nitrogen may be occurring. On the aft end of the wedge, peak heating for the nitrogen is seen to occur at gauge $\mathrm{M}$ and have a value of $\sim 10.5 \mathrm{MW} / \mathrm{m}^{2}$, and in air is $\sim 13 \mathrm{MW} / \mathrm{m}^{2}$. As in the M4_3.6 case, slighly higher heating values are seen in the case of the air on the aft cone in the vicinity of shock interaction with the surface. From the images it is observed that the shock interaction occurs just downstream of gauge L, which is in agreement with the heat transfer profiles. 

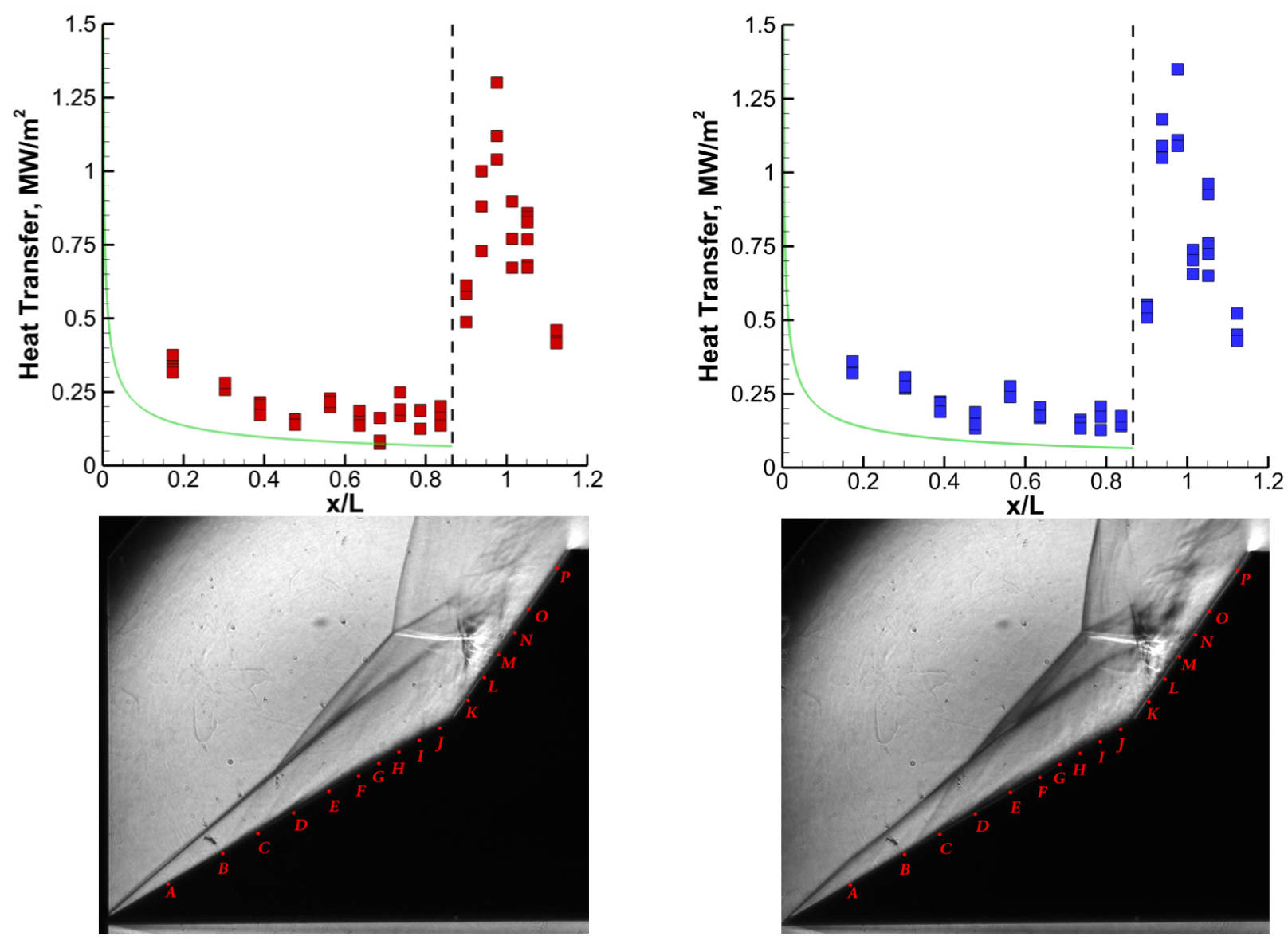

(a) $\mathrm{M}_{-} 2, \mathrm{~N}_{2}$

(b) M7_2, air

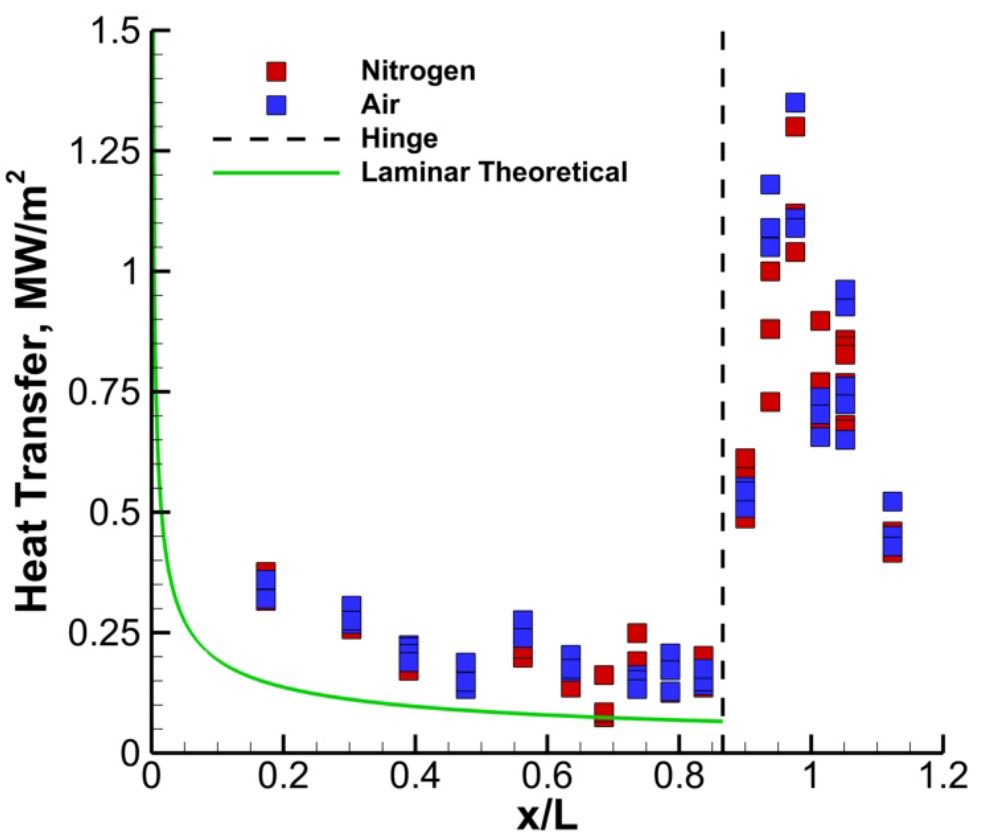

(c) Combined profiles

Figure 5. Heat transfer profiles for the M7_2 test condition in (a) $\mathrm{N}_{2}$, and (b) air. An overlay of the two profiles is shown in (c). The green line indicates a laminar flat plate calculation using the work of Simeonides. ${ }^{21}$ 

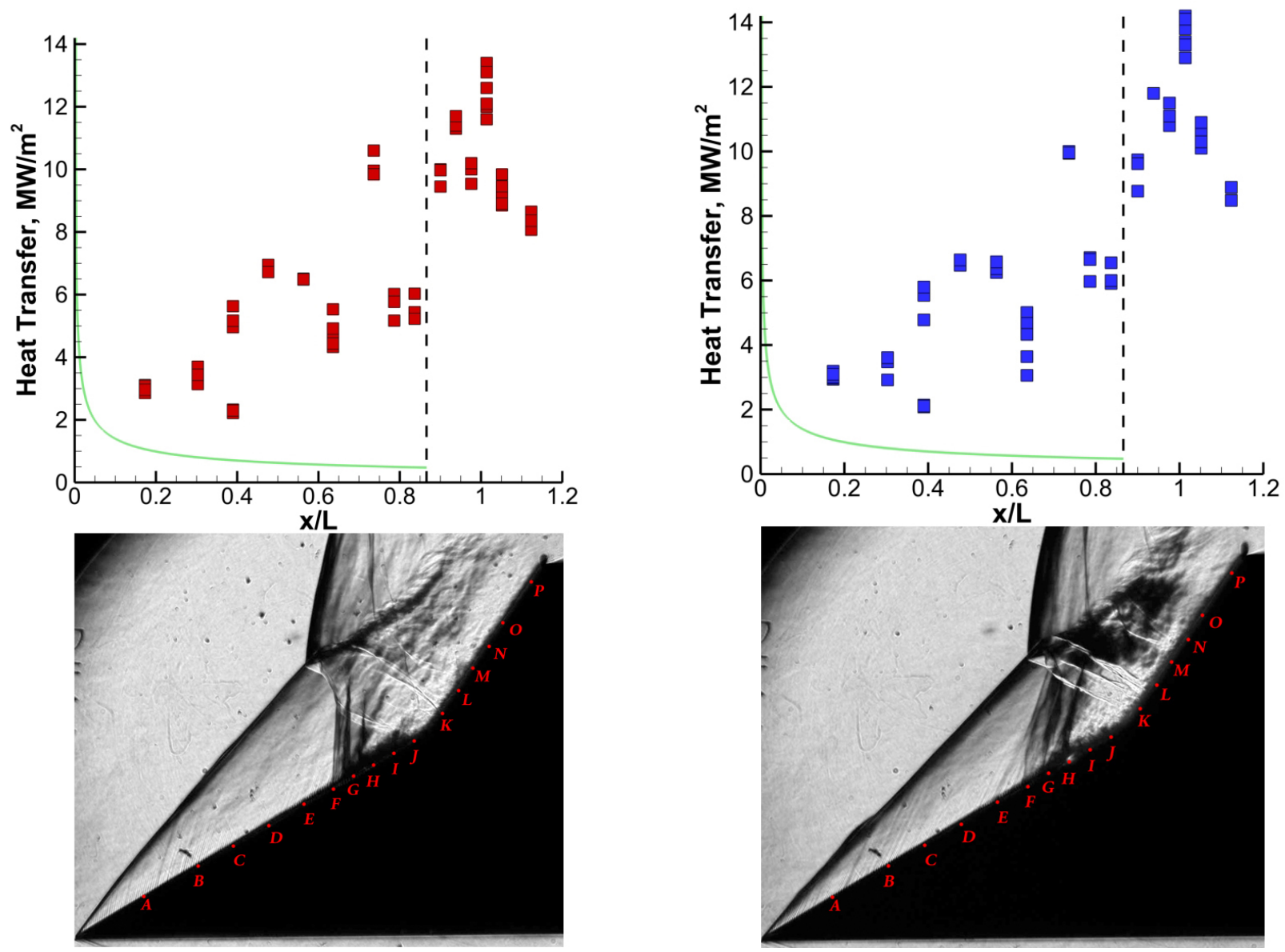

(a) M4_3.6, $\mathrm{N}_{2}$

(b) M4_3.6, air

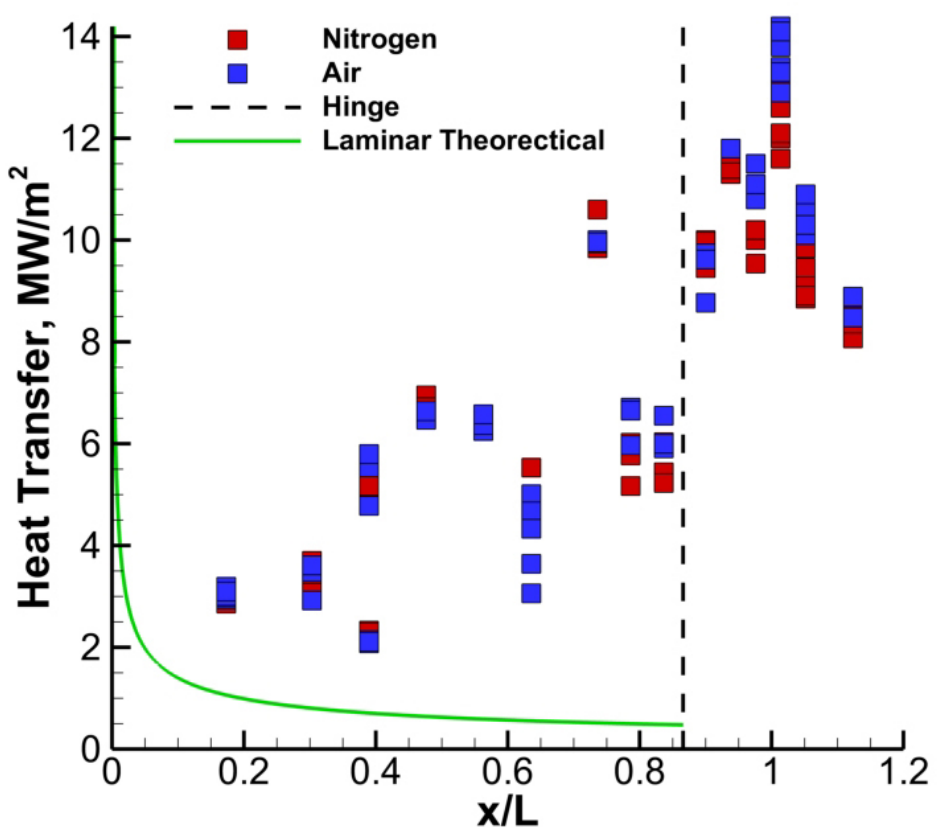

(c) Combined profiles

Figure 6. Heat transfer profiles for the M4_3.6 test condition in (a) $\mathrm{N}_{2}$, and (b) air. An overlay of the two profiles is shown in (c). The green line indicates a laminar flat plate calculation using the work of Simeonides. ${ }^{21}$ 

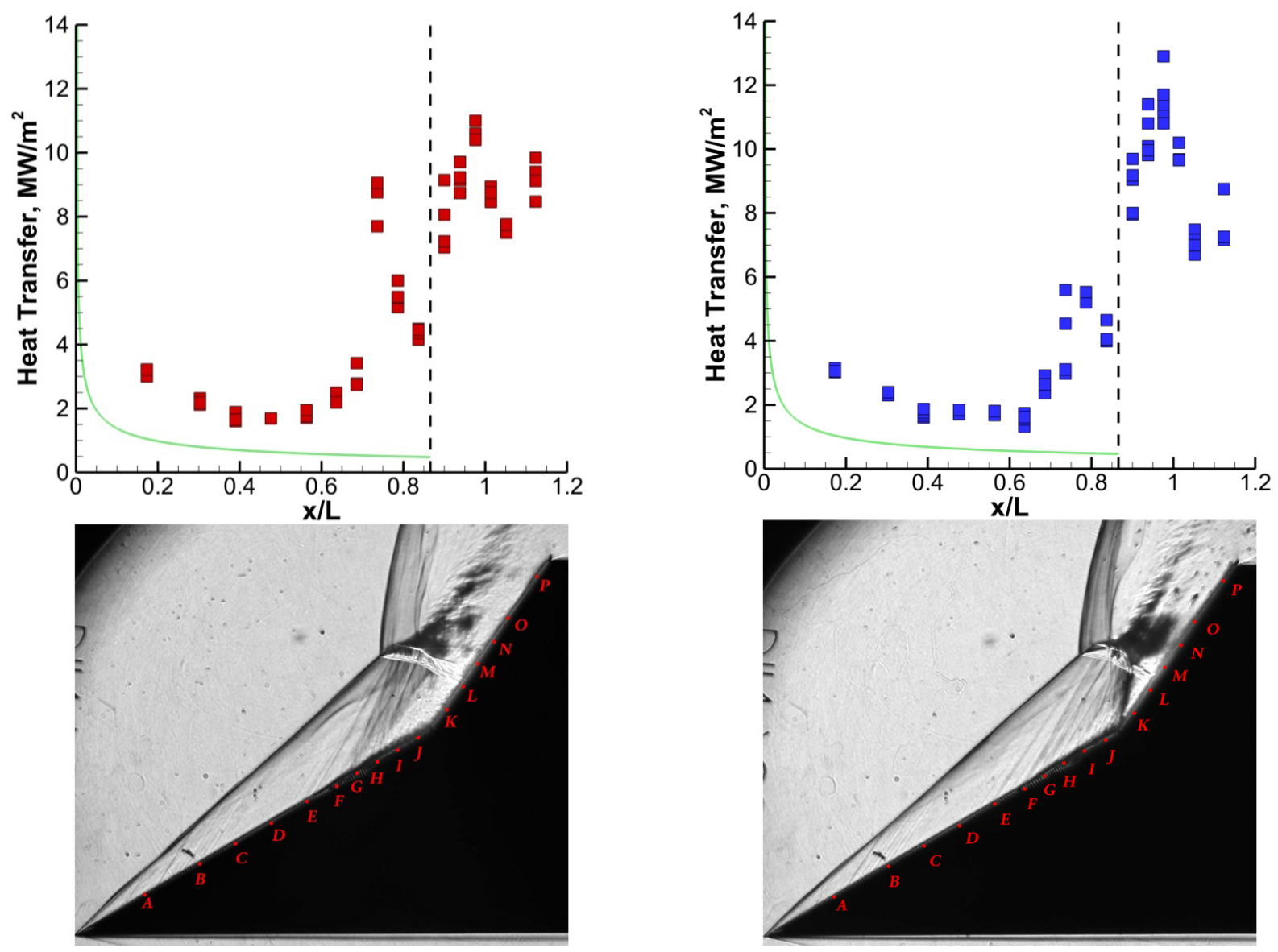

(a) M5_4, $\mathrm{N}_{2}$

(b) M5_4, air

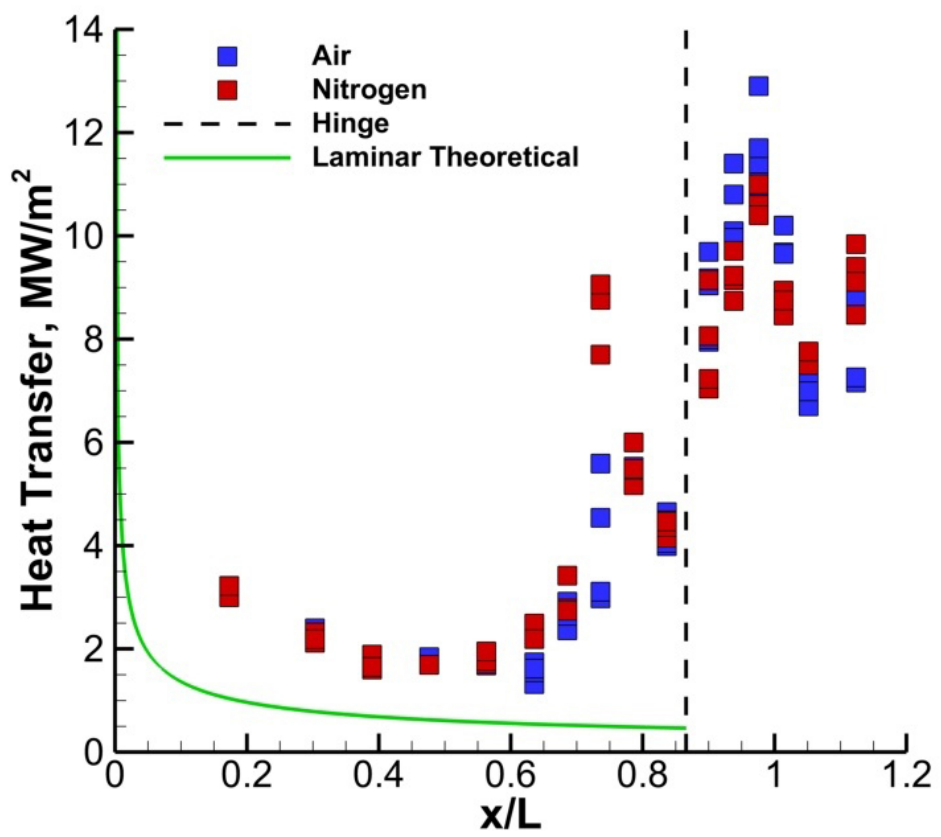

(c) Combined profiles

Figure 7. Heat transfer profiles for the M5_4 test condition in (a) $\mathrm{N}_{2}$, and (b) air. An overlay of the two profiles is shown in (c). The green line indicates a laminar flat plate calculation using the work of Simeonides. ${ }^{21}$ 


\section{III.B.4. M7_8 Test Condition}

Heat transfer data for the nitrogen and air along with the corresponding schlieren images for the highest Mach number and enthalpy condition are shown in Figures 8(a) and (b). In Figure 8(c) both heat transfer profiles are overlaid. On the upstream end of the forward wedges, the heat transfer corresponds reasonably well with laminar predictions. This is the only case where a slight difference is seen with respect to the two gases for laminar heating rates. The air values are consistently higher than the nitrogen, but are still within the error bars of the measurements. A distinct separation zone is seen in each plot as a decrease in heat transfer after $x / L=0.6$. In the nitrogen case, the separation zone appears to begin at gauge $\mathrm{F}$, and in the air case at gauge G. Perhaps the most noticeable difference between the two cases is the level of peak heating of the aft wedge. In nitrogen, the peak heating value is $8.5 \mathrm{MW} / \mathrm{m}^{2}$, while in air it is $13.5 \mathrm{MW} / \mathrm{m}^{2}$. In air, a dip in the heat transfer is observed just prior to the peak heating location. This may be the result of a secondary separation zone that lies upstream due to shock impingement, although this is difficult to discern due to the luminescence in the image. There is a considerable amount of variation in the data, not unexpectedly in the area of shock impingement on the aft wedge.

\section{Conclusions}

We investigate the hypersonic flows of nitrogen and air over a double wedge configuration at eight test conditions with stagnation enthalpies of 2 to $8 \mathrm{MJ} / \mathrm{kg}$. The shock wave-boundary layer interaction is investigated using single frame schlieren photography and fast response thermocouples to measure surface heat transfer.

At the $2 \mathrm{MJ} / \mathrm{kg}$ enthalpy condition, no appreciable difference between the air and nitrogen heat transfer distribution is observed over the entire model, as expected. Additionally, in the $3.6 \mathrm{MJ} / \mathrm{kg}$ condition, very little difference between the air and nitrogen conditions is observed. This condition also exhibits a deviation from the expected laminar heat transfer levels almost immediately on the first wedge surface in both gases.

Distinct differences between the air and nitrogen flows are apparent as low as $4 \mathrm{MJ} / \mathrm{kg}$ (M5_4 condition), indicating that gas thermochemistry plays a role at these enthalpies. For this case, thermochemical effects seem to be minimal toward the leading edge of the the front wedge where a laminar boundary layer is observed. As expected, these effects are most prominent in shock wave/boundary layer interaction regions. Aft wedge heating rates are systematically higher in air than in nitrogen in the region of shock impingement. We observe that in the case of the nitrogen flow, a departure from laminar boundary layer behavior occurs slightly upstream in comparison to the air flow.

Lastly, in the $8 \mathrm{MJ} / \mathrm{kg}$ test condition significant differences between the air and nitrogen are observed. Heat transfer levels on the forward wedge are slightly higher in air compared with nitrogen, although still within error bars. On the aft wedge peak heating is noticeably higher on in the air condition when compared with the nitrogen condition, again in the region of shock interaction.

\section{Acknowledgments}

This work was funded through the U.S. Air Force Office of Scientific Research (award FA 9550-11-1-0129) with Dr. John Schmisseur as program manager. Invaluable assistance with thermocouple instrumentation and data processing was provided by William Flaherty at Illinois. We are very grateful to Prof. Hans Hornung and the Caltech T5 group for the generous sharing of their thermocouple design and expertise.

\section{References}

\footnotetext{
${ }^{1}$ Olejniczak, J., Candler, G. V., Wright, M. J., Hornung, H. G., and Leyva, I., "High enthalpy double-wedge experiments," Proceedings of the AIAA Advanced Measurement and Ground Testing Technology Conference, New Orleans, LA, 1996.

${ }^{2}$ Davis, J. and Sturtevant, B., "Separation length in high-enthalpy shock/boundary layer interaction," Phys. Fluids, Vol. 12, No. 10, 2000, pp. 2661-87.

${ }^{3}$ Olejniczak, J., Wright, M. J., and Candler, G. V., "Numerical study of shock interactions on double-wedge geometries," Proceedings of the 34th AIAA Aerospace Sciences Meeting, Reno, NV, 1996.

${ }^{4}$ Edney, B. E., "Effects of Shock impingement on the heat transfer around blunt bodies," AIAA Journal, Vol. 6, No. 1, 1968, pp. 15-21.

${ }^{5}$ Olejniczak, J., Candler, G. V., Wright, M. J., Leyva, I., and Hornung, H. G., "Experimental and Computational study of high enthalpy double-wedge flows," J. Thermophys. and Heat Transfer, Vol. 13, No. 4, 1999, pp. 431-40.
} 

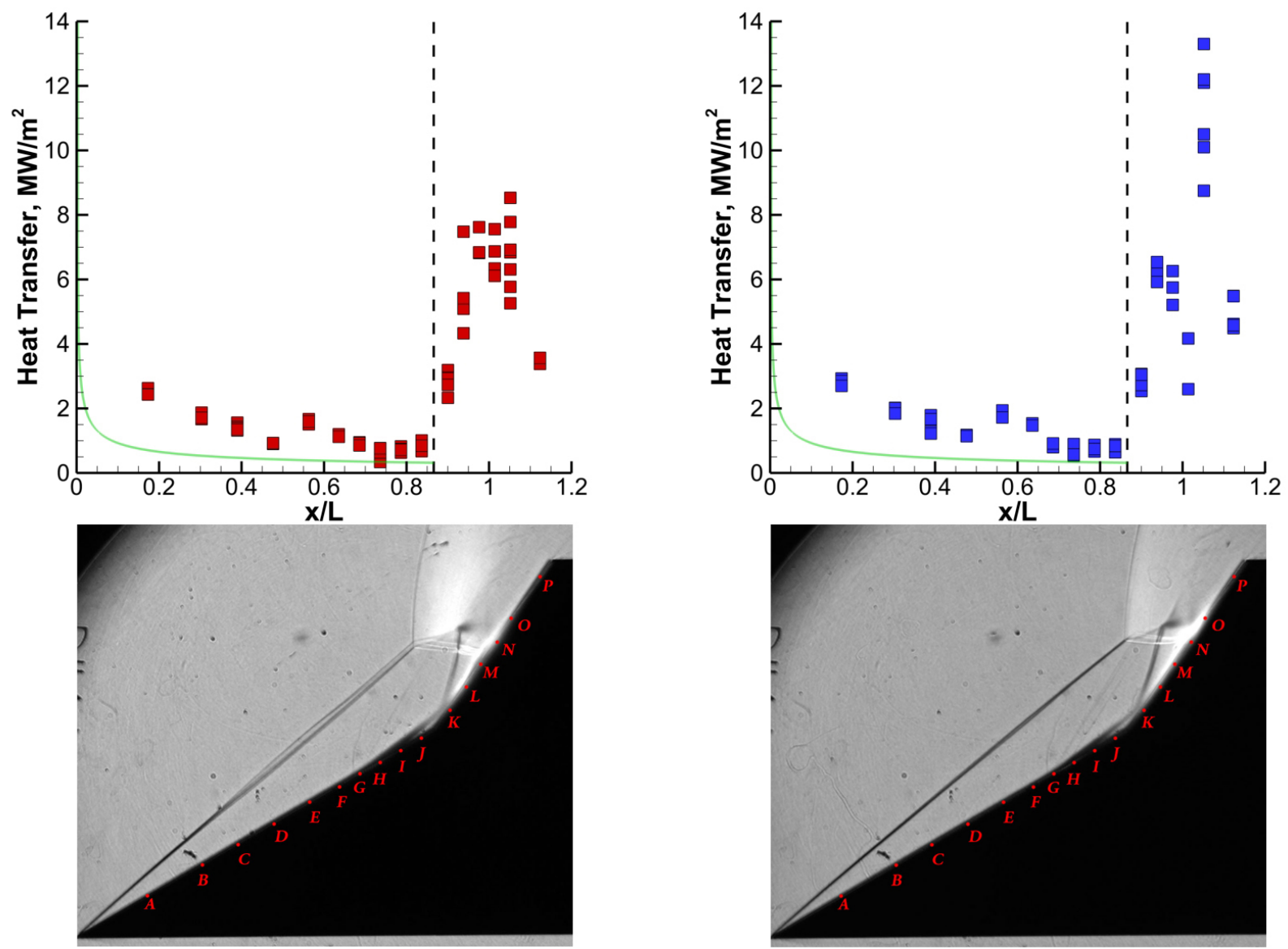

(a) $\mathrm{M} 7 \_8, \mathrm{~N}_{2}$

(b) M7_8, air

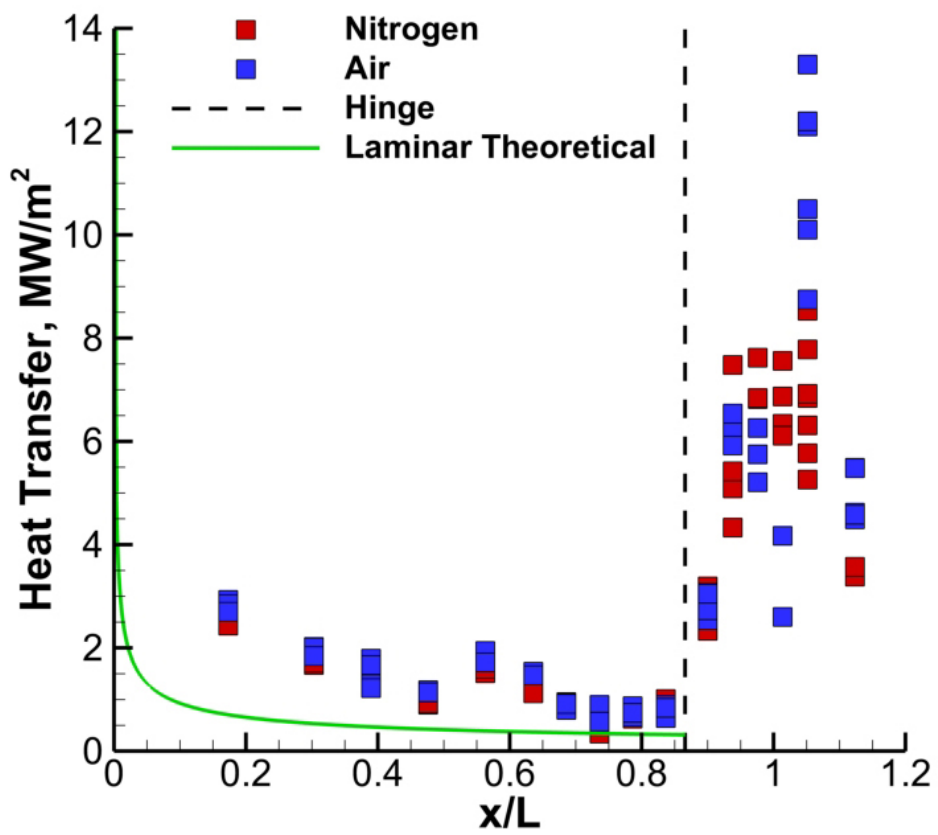

(c) Combined profiles

Figure 8. Heat transfer profiles for the M7_8 test condition in (a) $\mathrm{N}_{2}$, and (b) air. An overlay of the two profiles is shown in (c). The green line indicates a laminar flat plate calculation using the work of Simeonides. ${ }^{21}$

\section{1 of 12}


${ }^{6}$ Stewartson, K. and Williams, P. G., "Self-induced separation," Proc. R. Soc. London, Ser. A, Vol. 312, 1969, pp. 181. ${ }^{7}$ Sychev, V. V., "Asymptotic theory of separation flows," Fluid Dynamics, Vol. 17, 1982, pp. 1179.

${ }^{8}$ Roshko, A., "Free shear layers, base pressure and bluff-body drag," Symposium on Developments in Fluid Dynamics and Aerospace Engineering, Interline, Bangalore, 1995.

${ }^{9}$ Swantek, A. B. and Austin, J. M., "Separation length scaling in hypervelocity double cone air flows," Proceedings of the 28th International Symposium on Shock Waves, Manchester, England, UK, 2011.

${ }^{10}$ Nompelis, I. and Candler, G. V., "Investigation of hypersonic double-cone flow experiments at high enthalpy in the LENS facility," Proceedings of the 45nd AIAA Aerospace Sciences Meeting, Reno, NV, 2007.

${ }^{11}$ Nompelis, I., Candler, G. V., MacLean, M., Wadhams, T. P., and Holden, M. S., "Numerical investigation of double-cone flow experiments with high enthalpy effects," Proceedings of the 48rd AIAA Aerospace Sciences Meeting, Orlando, FL, 2010.

${ }^{12}$ Candler, G. V., Doraiswamy, S., and Kelley, J. D., "The potential role of electronically-excited states in recombining flows," Proceedings of the 48th AIAA Aerospace Sciences Meeting, Orlando, FL, USA, 2010.

${ }^{13}$ Nompelis, I., Candler, G. V., and Holden, M. S., "Effect of vibrational nonequilibrium on hypersonic double-cone experiments," AIAA Journal, Vol. 41, No. 11, 2003, pp. 2162-9.

${ }^{14}$ Parker, T. and Wakemman, T., "Measuring nitric oxide freestream velocity using quantum cascade lasers at CUBRC," Proceedings of the 45th AIAA Aerospace Sciences Meeting, Reno, NV, USA, 2007.

${ }^{15}$ Dufrene, A., Sharma, M., and Austin, J. M., "Design and characterization of a hypervelocity expansion tube facility," Journal of Propulsion and Power, Vol. 23, No. 6, Nov 2007, pp. 1185-1193.

${ }^{16}$ Flaherty, W., Crafton, J., Elliott, G., and Austin, J. M., "Application of fast pressure sensitive paint in hypervelocity flow," Proceedings of the 49th AIAA Aerospace Sciences Meeting, Orlando, FL, 2011.

${ }^{17}$ Browne, S., Ziegler, J., and Shepherd, J. E., "Numerical solution methods for shock and detonation jump conditions," Tech. rep., California Institute of Technology, Pasanda, Ca, August 2008, GALCIT Report FM2006.006.

${ }^{18}$ Goodwin, D., "An open-source, extensible software suite for CVD process simulation," Proc. of CVD XVI and EuroCVD Fourteen, 2003, pp. 155-162.

${ }^{19}$ Sanderson, S. R., Austin, J. M., Liang, Z., Pintgen, F., Shepherd, J. E., and Hornung, H. G., "Reactant jetting in unstable detonation," Progress in Aerospace Sciences, Vol. 46, No. 2-3, 2010, pp. 116-131.

${ }^{20}$ Pintgen, F., Eckett, C. A., Austin, J. M., and Shepherd, J. E., "Direct observations of reaction zone structure in propagating detonations," Combustion and Flame, Vol. 133, No. 3, 2003, pp. 211-229.

${ }^{21}$ Simeonides, G., "Generalized reference enthalpy formulations and simulations of viscous effects," Shock Waves, Vol. 8, No. 3, 1998, pp. 161-72. 